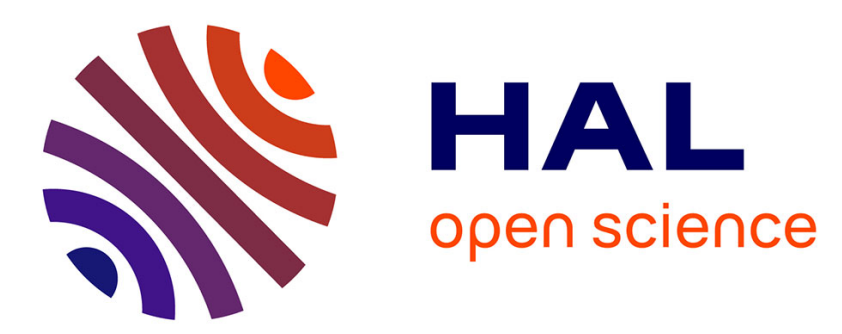

\title{
Stress intensity factor for an infinite transversely isotropic solid containing a penny-shaped crack
}

\author{
M. Dahan
}

\section{To cite this version:}

M. Dahan. Stress intensity factor for an infinite transversely isotropic solid containing a penny-shaped crack. Journal de Physique Lettres, 1980, 41 (9), pp.213-215. 10.1051/jphyslet:01980004109021300 . jpa-00231762

\section{HAL Id: jpa-00231762 https://hal.science/jpa-00231762}

Submitted on 1 Jan 1980

HAL is a multi-disciplinary open access archive for the deposit and dissemination of scientific research documents, whether they are published or not. The documents may come from teaching and research institutions in France or abroad, or from public or private research centers.
L'archive ouverte pluridisciplinaire HAL, est destinée au dépôt et à la diffusion de documents scientifiques de niveau recherche, publiés ou non, émanant des établissements d'enseignement et de recherche français ou étrangers, des laboratoires publics ou privés. 


\title{
Stress intensity factor for an infinite transversely isotropic solid containing a penny-shaped crack $\left({ }^{*}\right)$
}

\author{
M. Dahan \\ Laboratoire de Mécanique des Solides, Ecole Polytechnique (**), 91128 Palaiseau, France
}

(Reçu le 24 janvier 1980, accepté le 13 mars 1980)

\begin{abstract}
Résumé. - On donne la solution explicite du problème axi-symétrique quand des forces intérieures concentrées sur une surface, sont appliquées à une distance finie de la fissure. Pour des charges appliquées sur les lèvres de la fissure, les résultats donnés sont indépendants des coefficients élastiques et ont les mêmes valeurs que pour un milieu isotrope.
\end{abstract}

\begin{abstract}
A closed form solution of an axisymmetric problem is obtained when an interior surface concentrated loading is applied at a finite distance from the crack. For a general loading applied to the crack surface, the results are independent of the elastic constants and hence, they have the same values as in an isotropic case.
\end{abstract}

1. Introduction. - Let us consider a homogeneous elastic medium occupying the three-dimensional euclidian space, referred to a fixed rectangular cartesian coordinate system $(O x y z)$. We shall assume that the medium is characterized by transverse isotropy, having $z$-axis as elastic symmetry axis. By using the cylindrical coordinates $(r, \theta, z)$, we shall note $(u, 0, w)$ the components of the displacement field, $\left(\sigma_{r r}, \sigma_{\theta \theta}, \sigma_{z z}, \sigma_{r z}\right)$ the non-zero components of the stress tensor and $\left(\varepsilon_{r r}, \varepsilon_{\theta \theta}, \varepsilon_{z z}, \varepsilon_{r z}\right)$ the components of the strain tensor. Then, the strain-stress relations can be defined by :

$$
\begin{aligned}
& \varepsilon_{r r}=a_{11} \sigma_{r r}+a_{12} \sigma_{\theta \theta}+a_{13} \sigma_{z z}, \\
& \varepsilon_{\theta \theta}=a_{12} \sigma_{r r}+a_{11} \sigma_{\theta \theta}+a_{13} \sigma_{z z}, \\
& \varepsilon_{z z}=a_{13} \sigma_{r r}+a_{13} \sigma_{\theta \theta}+a_{33} \sigma_{z z}, \\
& \varepsilon_{r z}=a_{44} \sigma_{r z},
\end{aligned}
$$

where $a_{11}, a_{12}, a_{13}, a_{33}, a_{44}$ are the five independent elastic coefficients of the medium.

$\left(^{*}\right)$ La version française de cet article a été acceptée aux Comptes Rendus de l'Académie des Sciences et est insérée dans le $\mathrm{n}^{0} \mathrm{du}$ 14 janvier 1980.

$\left({ }^{* *}\right)$ ERA C.N.R.S. $n^{\circ} 455$.
The solid contains a penny-shaped crack defined by $0 \leqslant r \leqslant r_{0}, z=0$ and it is subjected to body forces field parallel to the $z$-axis, $F_{z}(r, z)$, assumed to be odd functions of $z$. In this case, we shall solve the equivalent problem for the half-space $z>0$, actionned internally by $F_{z}(r, z)$ and subjected to the mixed boundary conditions :

$$
\left.\begin{array}{rl}
\sigma_{r z}(r, 0)=0 & 0 \leqslant r<\infty, \\
\sigma_{z z}(r, 0)=0 & 0 \leqslant r<r_{0}, \\
w(r, 0)=0 & r_{0} \leqslant r<\infty .
\end{array}\right\}
$$

and regularity conditions at infinity.

Let us assume that the body forces $F_{z}$ are concentrated on a plane interior surface, round the $z$-axis, i.e. of the form :

$$
F_{z}(r, z)=p(r) \delta(z-h),
$$

where $p$ is an arbitrary function defined for $r \geqslant 0$ such as the Hankel transform of order zero $p^{\mathbf{H}}$ exists, $\delta$ is the Dirac distribution and $h$ is a positive constant.

In a previous paper [1], it has been shown that a potential function of the Love type exists for this problem and is defined by :

$$
\varphi(r, z)=\int_{0}^{\infty}\left[A(m) \mathrm{e}^{-m s_{1} z}+B(m) \mathrm{e}^{-m s_{2} z}+\frac{p^{\mathrm{H}}(m)}{2 m^{3} d\left(s_{1}^{2}-s_{2}^{2}\right)}\left(\frac{1}{s_{1}} \mathrm{e}^{-m s_{1}|z-h|}-\frac{1}{s_{2}} \mathrm{e}^{-m s_{2}|z-h|}\right)\right] J_{0}(m r) m \mathrm{~d} m,
$$


where the functions $A$ and $B$ are determined by the boundary conditions (2). In the last expression, we have used the following notations :

$$
\begin{aligned}
& a=a_{13}\left(a_{11}-a_{12}\right) /\left(a_{11} a_{33}-a_{13}^{2}\right), \\
& b=\left[a_{13}\left(a_{13}+a_{44}\right)-a_{12} a_{33}\right] /\left(a_{11} a_{33}-a_{13}^{2}\right), \\
& c=\left[a_{13}\left(a_{11}-a_{12}\right)+a_{11} a_{44}\right] /\left(a_{11} a_{33}-a_{13}^{2}\right), \\
& d=\left(a_{11}^{2}-a_{12}^{2}\right) /\left(a_{11} a_{33}-a_{13}^{2}\right),
\end{aligned}
$$

and :

$$
\begin{aligned}
& s_{1}=\left[\left(a+c+\sqrt{\left.(a+c)^{2}-4 d\right)} / 2 d\right]^{1 / 2},\right. \\
& s_{2}=\left[\left(a+c-\sqrt{\left.(a+c)^{2}-4 d\right)} / 2 d\right]^{1 / 2} .\right.
\end{aligned}
$$

Using the potential function, the boundary conditions (2) are given by :

$$
\begin{aligned}
\sigma_{r z}(r, 0) & =\left[\frac{\partial}{\partial r}\left(\frac{\partial^{2} \varphi(r, z)}{\partial r^{2}}+\frac{1}{r} \frac{\partial \varphi(r, z)}{\partial r}+a \frac{\partial^{2} \varphi(r, z)}{\partial z^{2}}\right)\right]_{z=0}=0, & 0 \leqslant r<\infty, \\
\sigma_{z z}(r, 0) & =\left[\frac{\partial}{\partial z}\left(c \frac{\partial^{2} \varphi(r, z)}{\partial r^{2}}+\frac{c}{r} \frac{\partial \varphi(r, z)}{\partial r}+d \frac{\partial^{2} \varphi(r, z)}{\partial z^{2}}\right)\right]_{z=0}=0, & 0 \leqslant r<r_{0}, \\
w(r, 0) & =\left[a_{44}\left(\frac{\partial^{2} \varphi(r, z)}{\partial r^{2}}+\frac{1}{r} \frac{\partial \varphi(r, z)}{\partial r}\right)+\left(a_{33} d-2 a_{13} a\right) \frac{\partial^{2} \varphi(r, z)}{\partial z^{2}}\right]_{z=0}=0, & r_{0} \leqslant r<\infty .
\end{aligned}
$$

2. Resolution. - First, we introduce the constants :

$$
\begin{aligned}
& p_{1}=1-a s_{1}^{2}, \quad p_{2}=1-a s_{2}^{2}, \\
& g_{1}=c-d s_{1}^{2}, \quad g_{2}=c-d s_{2}^{2}, \\
& f=(d-a c) / \sqrt{d} .
\end{aligned}
$$

Then, the condition (7) implies the relation :

$$
\begin{aligned}
B(m)= & -\frac{p^{\mathrm{H}}(m)}{2 m^{3} d\left(s_{1}^{2}-s_{2}^{2}\right)} \\
& \times\left(\frac{p_{1}}{s_{1} p_{2}} \mathrm{e}^{-m s_{1} h}-\frac{1}{s_{2}} \mathrm{e}^{-m s_{2} h}\right) \frac{p_{1}}{p_{2}} A(m) .
\end{aligned}
$$

If we introduce a supplementary function $\chi$ such that :

$$
\begin{array}{r}
{\left[A(m)+\frac{p^{\mathrm{H}}(m) \mathrm{e}^{-m s_{1} h}}{2 m^{3} d s_{1}\left(s_{1}^{2}-s_{2}^{2}\right)}\right] m^{3}=\frac{p_{2}}{\left(s_{1}-s_{2}\right) f} \times} \\
\times \int_{0}^{r_{0}} \chi(t) \sin (m t) \mathrm{d} t
\end{array}
$$

with $\chi(0)=0$, the condition (9), transformed by (11), is identically verified. The condition (8) can be reduced to an Abel integral equation for which the following solution exists

$$
\begin{aligned}
& \chi(t)=\frac{-2}{\pi d\left(s_{1}^{2}-s_{2}^{2}\right)} \int_{0}^{\infty}\left(g_{1} \mathrm{e}^{-m s_{1} h}-g_{2} \mathrm{e}^{-m s_{2} h}\right) \times \\
& \times p^{\mathrm{H}}(m) \sin (m t) \mathrm{d} m .
\end{aligned}
$$

Then, the stress intensity factor defined by the limit :

$$
k_{1}=\lim _{r \rightarrow r_{0}^{+}}\left[2 \pi\left(r-r_{0}\right)\right]^{1 / 2} \sigma_{z z}(r, 0),
$$

is equal to :

$$
k_{1}=\sqrt{\frac{\pi}{r_{0}}} \chi\left(r_{0}\right) .
$$

When the loads are applied on the crack surface, we have $h=0$ and, from (15), we deduce :

$$
k_{1}=\frac{2}{\sqrt{\pi r_{0}}} \int_{0}^{\infty} p^{\mathrm{H}}(m) \sin \left(m r_{0}\right) \mathrm{d} m .
$$

3. Discussion. - It is important to remark that the last result depends only on the loading $p(r)$ applied on the crack through its Hankel transform $p^{\mathrm{H}}(m)$. Thus, the elastic coefficients of the material do not appear in formula (16), and, therefore, every result existing previously for the stress intensity factors in an isotropic medium is generalizable to a transversely isotropic medium when the loads are applied on the crack surfaces. This is surely not true when $h$ is different from zero.

The expressions (15) and (16) give closed form results to most of the loadings. Specially, we obtain for a uniform load $p_{0}$ over a circular area of radius $r_{1}$, below $r_{0}$, and at a non-zero distance $h$ from the crack ;

$k_{1}=\frac{2 p_{0} \sqrt{r_{0}}}{\sqrt{\pi} d\left(s_{1}^{2}-s_{2}^{2}\right)} \sum_{i=1}^{2}(-1)^{i} g_{i}\left[1-s_{i} h /\left(r_{0} \alpha_{i}-r_{0}\right)\right]$, 
with :

$$
\begin{aligned}
\alpha_{i}^{2}= & \frac{1}{2}\left\{\frac{r_{1}^{2}}{r_{0}^{2}}+\frac{s_{i}^{2} h^{2}}{r_{0}^{2}}-1+\right. \\
& \left.+\left[\left(\frac{r_{1}^{2}}{r_{0}^{2}}+\frac{s_{i}^{2} h^{2}}{r_{0}^{2}}-1\right)^{2}+4 \frac{s_{i}^{2} h^{2}}{r_{0}^{2}}\right]^{1 / 2}\right\} .
\end{aligned}
$$

If the loading is actionned over the crack surfaces, we can tend $h$ to zero and we deduce :

$$
k_{1}=\frac{2}{\sqrt{\pi}} p_{0} \sqrt{r_{0}}\left[1-\left(1-r_{1}^{2} / r_{0}^{2}\right)^{1 / 2}\right] \text {. }
$$

This last expression generalizes Sneddon's result [2] given for an isotropic material.

\section{References}

[1] Dahan, M., Predeleanu, M., C. R. Hebd. Séan. Acad. Sci., Paris 289 (1979) 147
[2] Kassir, M. K., SiH, G. C., Three dimensional crack problems (Noordhoff Int. Publishing, Leyden) 1975. 